\title{
Socio-economic inequality in unhealthy snacks consumption among adolescent students in Iran: a concentration index decomposition analysis
}

\author{
Vahid Yazdi-Feyzabadi ${ }^{1}$, Arash Rashidian ${ }^{2,3}$ and Mostafa Amini Rarani ${ }^{4, *}$ \\ 'Health Services Management Research Center, Institute for Futures Studies in Health, Kerman University of Medical \\ Sciences, Kerman, Iran: ${ }^{2}$ Department of Health Management and Economics, School of Public Health, Tehran \\ University of Medical Sciences, Tehran, Iran: ${ }^{3}$ Department of Information, Evidence and Research, World Health \\ Organization, Eastern Mediterranean Region, Cairo, Egypt: ${ }^{4}$ Health Management and Economics Research Center, \\ Isfahan University of Medical Sciences, Isfahan Iran, School of Management and Medical Information Sciences, \\ Isfahan University of Medical Sciences, Hezar Jerib Avenue, 8174673461 Isfahan, Iran
}

Submitted 12 March 2018: Final revision received 24 January 2019: Accepted 11 February 2019: First published online 14 June 2019

\begin{abstract}
Objective: The present study aimed to assess and decompose the socio-economic inequality in unhealthy snacks consumption among adolescent students in Kerman, Iran.

Design: The data were obtained from a cross-sectional study. Principal component analysis was done to measure the socio-economic status (SES) of the adolescents' families and the normalized concentration index (NCI) was used to measure the inequality in unhealthy snacks consumption among adolescent students of different SES. The contributions of environmental and individual explanatory variables to inequality were assessed by decomposing the concentration index.

Setting: Forty secondary schools of Kerman Province in Iran in 2015.

Participants: Eighth-grade adolescent students ( $n$ 1320).

Results: The data of 1242 adolescent students were completed for the current study. Unhealthy snacks consumption was unequally distributed among adolescent students and was concentrated mainly among the high-SES adolescents ( NCI $=0 \cdot 179$; $95 \%$ CI 0.056, 0.119). The decomposition showed that higher SES (62\%) and receiving pocket money allowance (31\%), as environmental variables, had the highest positive contributions to the measured inequality in unhealthy snacks consumption. Taste and sensory perception (7\%) as well as cost sensitivity $(5 \%)$, as individual variables, followed them in terms of their contribution importance.

Conclusions: It is highly suggested that both environmental and individual factors should be addressed at different settings including schools, families and suppliers of unhealthy snacks. These findings can help future health promotion strategies in Iran to tackle the observed inequality in unhealthy snacks consumption.
\end{abstract}

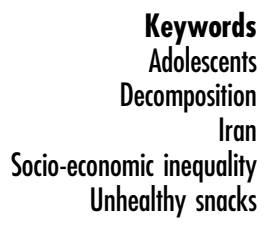

Nowadays, as shown in many studies, snacks provide a considerable proportion of daily energy intake ${ }^{(1-3)}$. However, the important point is the type and amount of snacks a person eats. As highlighted in the nutrient profile model of the WHO, less healthy foods are usually defined as foods that are high in energy, saturated fats, trans-fatty acids, salt and sugar but low in nutrients ${ }^{(4)}$. In Iran, the Community Nutrition Improvement Department of the Ministry of Health and the Health Affairs Office affiliated with the Ministry of Education have jointly developed a healthy canteen guideline. In this guideline, snacks that are low in nutrients and high in fat, sugar and salt are considered unhealthy ${ }^{(5)}$.

Adolescents' dietary decisions have turned into a big worry in recent years. Unhealthy eating behaviours and habits are claimed as risk factors for non-communicable diseases such as cancer, obesity, high blood pressure, CVD and diabetes. Although chronic diseases are not predominant among young people, there is developing proof that risk factors begin early in life ${ }^{(6)}$. Thus, a strong 
predictor of overweight and obesity is junk food consumption $^{(7)}$. A national survey conducted on Iranian children and adolescents aged 6 to 18 years concluded that the intake of sweets, fast foods, sweet beverages and salty snacks was significantly associated with some anthropometric indices and blood pressure levels. In addition, children and adolescents who consumed sweet beverages daily were at a higher risk of general obesity ${ }^{(8)}$.

Overweight and obesity are now major public health challenges that also show a more or less increasing trend in Iran. Results of national surveys on the risk factors of non-communicable diseases show that the overall prevalence of obesity among adults aged 25 to 64 years has increased from $13.6 \%$ in 1999 to $22.3 \%$ in 2007 . For overweight, the rates were 32.2 and $36.3 \%$, respectively ${ }^{(9)}$. Furthermore, the results of a systematic review showed that the overweight prevalence trend in Iranian children aged 7 to 11 years has increased from $10 \cdot 4$ to $10 \cdot 8 \%$ during 2005 to $2010^{(10)}$. In another systematic review, the range of overweight and obesity prevalence in national studies was $5 \cdot 0-13.5$ and $3 \cdot 2-11.9 \%$, respectively ${ }^{(11)}$.

Improved food habits among adolescents are probably going to lessen the population-based rate of chronic diseases, since these habits set up at an early age to adulthood $^{(12)}$. Food habits are also profoundly relevant in terms of social inequalities in health, because dietary imbalance is linked to health inequality ${ }^{(13)}$. Policy makers worldwide are concerned with socio-economic inequality in health and, hence, its mitigation is a key public health priority ${ }^{(6,14)}$. In this regard, some evidence shows a relationship between low socio-economic status (SES) and higher risk of morbidity and mortality, especially for noncommunicable diseases ${ }^{(15,16)}$. Also, it is suggested that SES may create and distribute (un)healthy behaviours ${ }^{(17)}$. It is important to study SES-related inequalities in health behaviours, particularly in the adolescence period, since they can form future patterns of adult health status ${ }^{(18)}$. Dietary and nutritional behaviours are among the most common behaviours that are differently distributed among high- and low-SES groups.

According to several studies, food consumption in adolescents is related to socio-economic factors such as parental education $^{(16)}$, parental occupation ${ }^{(17)}$ and household income ${ }^{(18)}$. It is claimed that socio-economic factors can explain some food consumption patterns among different socio-economic groups ${ }^{(1)}$. For example, groups with low socio-economic level are associated with lower consumption of healthy foods ${ }^{(2,3)}$. Inequality in food consumption is important to understand because it is a key element of inequality in overall health during the lifespan ${ }^{(4)}$ as well as an explanatory contributor to such inequality. A few studies have explored the role of schools in food consumption inequality ${ }^{(1)}$.

For the first time in Iran, we hypothesized in the present study that unhealthy snacks consumption was unequally distributed among adolescents with different SES. This hypothesis was tested via the concentration index method. We also tested the contribution of explanatory variables to inequality in unhealthy snacks consumption using decomposition of the concentration index. Better understanding of the attributable factors in distribution of unhealthy snacks consumption could provide insight for policy makers to redesign school-based interventions, such as the Iranian Health Promoting School (IHPS) programme. So, the aims of the present study were to examine the socioeconomic inequality in unhealthy snacks consumption and to decompose the measured inequality among adolescent students in Kerman Province.

\section{Methods}

\section{Data}

The data used in the present study were obtained from a cross-sectional survey conducted in forty secondary schools of Kerman Province in Iran in 2015. The participants were selected through the proportional stratified random sampling method. The sample population included 1320 eighth-grade adolescent students. The schools were randomly selected from the provincial list of schools stratified by gender, type of school (public/private) and involvement in the IHPS programme (IHPS/non-IHPS). More details about the sample size and sampling method are presented elsewhere ${ }^{(19)}$.

\section{Definition of variables}

Unhealthy snacks consumption was selected as a binary outcome variable; that is, whether each of the adolescent students consumed a high level of unhealthy snacks during one week prior to the study. Unhealthy snacks included thirty-two snacks with added salt, sugar and fat based on the national rule set for unhealthy foods in school canteens $^{(20)}$. As the mentioned national rule defined no cut-off point to distinguish between high and low levels of unhealthy snacks consumption, the median was used as the cut-off point to distinguish between the students in terms of their levels of unhealthy snacks consumption. Hence, we developed a binary variable comprising a 'low' and a 'high' level of unhealthy snacks consumption. It is notable that we used the high level of unhealthy snacks consumption for measuring and decomposing inequality.

It is evident that a wide range of individual and environmental factors may theoretically affect eating behaviours in adolescents $^{(21)}$. For this reason, we selected the explanatory variables according to a previous study conducted to determine the factors affecting adolescents' unhealthy snacks consumption ${ }^{(19)}$. Thus, for better understanding, the variables were categorized into individual and environmental factors. The individual factors included the students' gender (male/female), taste and sensory perception, perceived self-efficacy, nutritional knowledge, cost sensitivity 
(completely disagree, disagree, unsure, agree, completely agree) and self-body image (very underweight, underweight/fitness, slightly overweight, very obese). The environmental factors included family structure (dual-parent, single-parent/living with others), receiving pocket money allowance (yes/no), SES, school size ( $\leq 150,151-300$ and >300), snacks sold at school (yes/no), school type (public/ private), school with IHPS programme (IHPS/non-IHPS), social norms pressure, perceived parental control, media advertisements and easy accessibility of unhealthy snacks. The IHPS is a whole-school programme focused on improving high-risk behaviours of adolescents in Iran. In some Iranian schools, this programme is implemented and one of the components covered is nutritional behaviours ${ }^{(22)}$.

The SES of the adolescents' families was constructed using principal component analysis ${ }^{(23)}$. The following variables were used in the principal component analysis: mother's and father's educational level (illiterate, primary school, secondary school, high school and university), their occupational status, type of house ownership, number of rooms per capita and possession of private room (i.e. adolescent having his/her own bedroom without sharing it). To avoid multicollinearity, a $Z$-score of the first component was extracted and subsequently grouped into five SES quintiles including the poorest, poorer, middle, richer and the richest.

\section{Description of main measures}

Three items with a 5-point Likert scale (ranging from 'strongly disagree' $=1$ to 'strongly agree' $=5$ ) were used to assess taste and sensory perception, which indicated to what extent the adolescents agreed that better taste and appeal of unhealthy snacks stimulated them to consume junk foods. Perceived self-efficacy, including three items with response options ranging from 1 ('not at all confident') to 5 ('extremely confident'), was used as the adolescents' belief in their ability to succeed in controlling unhealthy snacks consumption and weight gain. For example, one item was: 'How confident are you that if you want, you can reduce the consumption of certain unhealthy snacks?' In the case of the nutritional knowledge measure, the ability to differentiate between the most common healthy and unhealthy snacks was asked through four multiple-choice questions (e.g. 'Which of the following items is a healthy drink?'). The total score ranged from 0 (none of the questions was correctly answered) to 4 (all four questions were correctly answered).

Cost/price sensitivity was a single item measured with a 5-point Likert scale (ranging from 'very low' $=1$ to 'very high' $=5$ ) in which the adolescents were asked to indicate their extent of agreement with the item: 'Because unhealthy snacks are less expensive I eat them'. This measure indicated whether the students were cost/price-sensitive to junk foods or not. Self-body image was a single-item variable denoting the body fitness perceived by the adolescents (ranging from 'very underweight' $=1$ to 'very obese' $=5$ ).
Social norms pressure refers to the pressure exercised by peers, friends, family and generally society to consume junk foods. It was assessed using seven items with a 5-point Likert scale (from 'strongly disagree' $=1$ to 'strongly agree' $=5$ ). For example, one of the statements presented was: 'Society expects me as an adolescent to eat unhealthy snacks'.

Perceived parental control was a three-item variable measuring the control of parents over the consumption of junk foods. For example, one statement included was: 'My parents tell me how much junk food I may consume'. The response options ranged from 'strongly disagree' $=1$ to 'strongly agree' $=5$.

Media advertisements included two items to measure the extent to which the adolescents agreed that advertisements on television/radio or local outdoor advertisements stimulated junk foods consumption. A statement used to measure this variable was: 'Advertisement on television or radio stimulates me to eat unhealthy snacks'. The response options were the same as for other measures.

Easy accessibility, a two-item measure with 5-point Likert scale, referred to the easiness of access to unhealthy snacks at home or in shops. One item of this variable was: 'If I had access to unhealthy snacks at home, it would make it more difficult for me to avoid them'. More details about these measures, content and face validity and their reliability are presented elsewhere ${ }^{(19)}$.

\section{Measuring inequality}

Inequality in unhealthy snacks consumption was assessed using the concentration index (CI) approach ${ }^{(24)}$, which is widely used to measure inequality in health ${ }^{(25,26)}$. The CI is defined based on a concentration curve ${ }^{(24)}$. The concentration curve plots the cumulative percentage of the health variable (vertical axis) against the cumulative percentage of individuals, ranked by their SES from the poorest to the richest (horizontal axis). If everyone, regardless of their SES, has precisely the same value of the health variable, the concentration curve will be a $45^{\circ}$ line named the line of equality. In comparison, if the health variable takes higher (lower) values among the poor, the concentration curve will lie above (below) the line of equality. The further the curve is above (below) the line of equality, the more concentrated the health variable is among the low-SES individuals (high-SES individuals). The CI is measured as twice the covariance of a health variable and fractional rank of a socio-economic variable divided by the mean healthrelated variable, as follows:

$$
C=\frac{2}{n \mu} \sum_{y=1}^{n} y_{i} R_{i}-1,
$$

where $y_{i}$ denotes the health variable (i.e. unhealthy snacks consumption) of the $i$ th adolescent student, $n$ denotes sample size, $\mu$ indicates its mean and $R_{i}$ denotes the fractional 
rank of the $i$ th adolescent student in terms of the index of his/her SES. CI values can vary between -1 and +1 ; the negative and positive values indicate that inequality disproportionally concentrates on the low- and high-SES individuals, respectively, and it will be zero in the case of equality ${ }^{(24)}$. In the present study, the unhealthy snacks consumption was a binary variable. Wagstaff's CI normalization was used to measure inequality in unhealthy snacks consumption $^{(27)}$ as follows:

$$
\mathrm{CI}_{\text {normalized }}=\frac{C}{1-\mu}
$$

\section{Decomposing inequality}

Decomposition of CI into its determinants identifies the contribution of each explanatory variable to the measured health inequality (e.g. unhealthy snacks consumption). Following Wagstaff et $a l^{(28)}$, for any linear regression model linking unhealthy snacks consumption $(y)$ to a set of $k$ explanatory variables $\left(x_{k}\right)$ :

$$
y_{i}=\alpha+\sum_{k} \beta_{k} x_{k i}+\varepsilon_{i}
$$

where $\alpha$ is parameter vector, $x_{k i}$ is a set of $k$ repressor variables for the $i$ th student, $\beta_{k}$ denotes the coefficient and $\varepsilon_{i}$ is an error term. Given the association of $y_{i}$ and $x_{k i}$ in equation (3), CI for $y$ can be written as:

$$
C=\sum_{k}\left(\frac{\beta_{k} \bar{x}_{k}}{\mu}\right) C_{k}+\frac{G C_{\varepsilon}}{\mu}=C_{\hat{y}}+\frac{G C_{\varepsilon}}{\mu},
$$

where $\mu$ is the mean of $y, \bar{x}_{k}$ is the mean of $x_{k}, C_{k}$ is the concentration index for $x_{k}$ defined precisely like $C$ (namely, normalized CI (NCI)), $\beta_{k} \bar{x}_{k} / \mu$ is the elasticity of unhealthy snacks consumption with explanatory variables and $G C_{\varepsilon}$ is the generalized CI for $\varepsilon_{i}$ (residual component). Equation (4) is composed of the deterministic or explained component (the left-hand side of the equation, denoted with $C_{\hat{y}}$ ) and the unexplained or residual component (the right-hand side). The former indicates the amount of inequality that can be explained by the explanatory variables included in the regression model. The latter is the part of the inequality that cannot be defined by systematic variation in the explanatory variables across SES classes. To decompose, one needs first to conduct a suitable regression model in order to calculate coefficients of the explanatory variables. In the current study, unhealthy snacks consumption was considered as a binary variable. Thus, following Yiengprugsawan et $a l .^{(29)}$, we applied a generalized linear model to calculate the coefficients. In generalized linear models, the explanatory variables are not sensitive to the choice of reference groups.

The absolute contribution of each explanatory variable to inequality can be identified by equation (4). The percentage contribution of each variable can also be calculated through the division of absolute contribution by the measured CI (of unhealthy snacks consumption). All analyses were done using the statistical software package Stata version $14 \cdot 0$.

\section{Results}

The data of 1242 adolescent students were complete and analysed in the current study. Table 1 shows brief statistics of unhealthy snacks consumption and its explanatory variables. About half of the adolescent students consumed unhealthy snacks. Regarding environmental variables, the majority of the adolescent students were in the middle category of SES, living with both parents and received pocket money allowance regularly. Snacks were sold in $85 \%$ of the schools. Forty-eight per cent of the adolescent students were highly subjected to snack advertisements and $47 \%$ of them had easy access to snacks at home and in shops. Regarding individual variables, about two-thirds of the students (69\%) imagined their bodies to be underweight or fit and more than half of them were not cost-sensitive. Over two-thirds of the adolescent students (69\%) had low taste and sensory perception and $60 \%$ had a low perceived self-efficacy.

Figure 1 depicts the concentration curve for unhealthy snacks consumption. As illustrated, the curve is below the line of equality with a positive value of $0.179(95 \%$ CI $0.056,0.119$ ) and indicates that unhealthy snacks consumption is more concentrated among adolescent students belonging to households with higher SES. In other words, it indicates that there is inequality in the distribution of unhealthy snacks consumption disfavouring those of high SES in Kerman, Iran (Table 2).

The results of decomposition of unhealthy snacks consumption according to the environmental and individual variables are presented in Table 3. The NCI of the explanatory variables including IHPS programme, (very) underweight, high perceived self-efficacy and low parental control, high cost sensitivity and high nutritional knowledge were negative, implying that all were more concentrated among adolescent students of lower SES. In contrast, private schools, students living with both parents, pocket money allowance, overweight, small-size schools, low cost sensitivity, low social norms pressure and easy access to unhealthy foods were more concentrated in adolescent students of higher SES. Regarding the contribution of the explanatory variables, if the value of the contribution of variable $X$ is $x$ and positive (negative), the inequality in unhealthy snacks consumption would decrease (increase) by $x \%$ if the variable was equally distributed among the SES groups. The largest contribution to inequality in unhealthy snacks consumption was attributed to SES (about $62 \%$ ) which was an environmental variable; that is, if educational and occupational opportunities as well as economic resources were equally distributed among households, the inequality in unhealthy snacks consumption would decline by $62 \%$. Another environmental 
Table 1 Summary statistics about unhealthy snacks consumption and its determinants among eighth-grade adolescent students ( $n$ 1242) from forty secondary schools of Kerman Province in Iran, 2015

\begin{tabular}{|c|c|c|c|}
\hline Variable & Mean & SD & $\%$ \\
\hline Unhealthy snacks consumption & 0.509 & 0.500 & $50 \cdot 97$ \\
\hline \multicolumn{4}{|c|}{ Environmental explanatory variables } \\
\hline \multicolumn{4}{|l|}{ Socio-economic status } \\
\hline Poorest & 0.200 & 0.400 & 3.70 \\
\hline Poorer & 0.199 & 0.399 & 8.86 \\
\hline Middle & 0.200 & 0.400 & $48 \cdot 71$ \\
\hline Richer & 0.199 & 0.399 & 33.98 \\
\hline Richest & 0.199 & 0.399 & 4.75 \\
\hline \multicolumn{4}{|l|}{ IHPS programme } \\
\hline Yes & 0.425 & \multirow[t]{2}{*}{0.494} & 42.59 \\
\hline No & 0.574 & & 57.41 \\
\hline \multicolumn{4}{|l|}{ School type } \\
\hline Private & 0.369 & \multirow[t]{2}{*}{0.482} & 36.96 \\
\hline Public & 0.630 & & 63.04 \\
\hline \multicolumn{4}{|l|}{ Family structure } \\
\hline Dual-parent & 0.909 & \multirow[t]{2}{*}{$0 \cdot 286$} & $90 \cdot 98$ \\
\hline Single-parent/others & 0.090 & & 9.02 \\
\hline \multicolumn{4}{|l|}{ Pocket money allowance } \\
\hline Yes & 0.819 & \multirow[t]{2}{*}{0.384} & 81.96 \\
\hline No & $0 \cdot 180$ & & 18.04 \\
\hline \multicolumn{4}{|l|}{ School size } \\
\hline$\leq 150$ & 0.346 & 0.475 & 34.62 \\
\hline $151-300$ & 0.373 & 0.483 & $37 \cdot 36$ \\
\hline$>300$ & 0.346 & 0.449 & 28.02 \\
\hline \multicolumn{4}{|l|}{ Snacks sold at school } \\
\hline Yes & 0.851 & \multirow[t]{2}{*}{0.355} & $85 \cdot 19$ \\
\hline No & 0.148 & & $14 \cdot 81$ \\
\hline \multicolumn{4}{|l|}{ Social norms pressure } \\
\hline High & 0.264 & \multirow[t]{2}{*}{0.441} & $26 \cdot 44$ \\
\hline Low & 0.735 & & 73.56 \\
\hline Perceived parental control & & & \\
\hline High & 0.288 & 0.453 & $28 \cdot 82$ \\
\hline Low & 0.711 & & $71 \cdot 18$ \\
\hline Media advertisements & & & \\
\hline High & 0.483 & 0.499 & $48 \cdot 39$ \\
\hline Low & 0.516 & & 51.61 \\
\hline Easy accessibility & & & \\
\hline High & 0.471 & 0.499 & $47 \cdot 18$ \\
\hline Low & 0.528 & & $52 \cdot 82$ \\
\hline Individual explanatory variables & & & \\
\hline Gender & & & \\
\hline Male & 0.521 & 0.499 & $52 \cdot 17$ \\
\hline Female & 0.478 & & $47 \cdot 83$ \\
\hline Self-body image & & & \\
\hline Very underweight & 0.048 & 0.214 & 4.83 \\
\hline Underweight/fitness & 0.687 & 0.402 & $68 \cdot 76$ \\
\hline Little overweight & $0 \cdot 217$ & 0.412 & $21 \cdot 74$ \\
\hline Very obese & 0.046 & 0.211 & 4.67 \\
\hline Cost sensitivity & & & \\
\hline Very high & 0.344 & 0.475 & 34.46 \\
\hline High & 0.298 & 0.457 & 29.87 \\
\hline Unsure & 0.243 & 0.429 & 24.32 \\
\hline Low & 0.081 & 0.273 & $8 \cdot 13$ \\
\hline Very low & 0.032 & 0.176 & 3.22 \\
\hline Taste and sensory perception & & & \\
\hline High & 0.304 & 0.460 & $30 \cdot 43$ \\
\hline Low & 0.695 & & 69.57 \\
\hline Perceived self-efficacy & & & \\
\hline High & 0.395 & 0.489 & 39.53 \\
\hline Low & 0.604 & & $60 \cdot 47$ \\
\hline Nutritional knowledge & & & \\
\hline High & 0.500 & 0.500 & $50 \cdot 00$ \\
\hline Low & 0.500 & & $50 \cdot 00$ \\
\hline
\end{tabular}

IHPS, Iranian Health Prooting School.

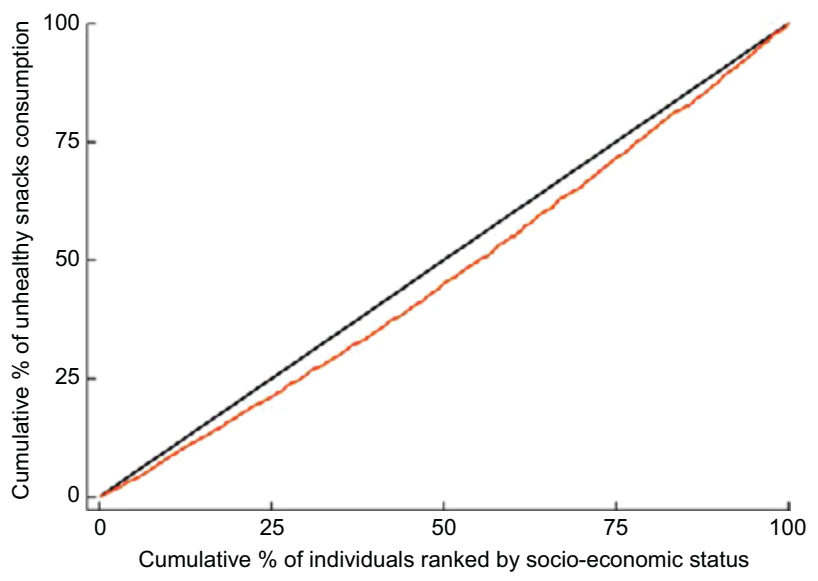

Fig. 1 (colour online) The concentration curve $(-)$ for unhealthy snacks consumption among eighth-grade adolescent students ( $n$ 1242) from forty secondary schools of Kerman Province in Iran, 2015. _ represents the line of equality

Table 2 Normalized concentration index (NCl), $95 \% \mathrm{Cl}$, SE and $P$ value for consumption of unhealthy snacks among eighth-grade adolescent students $(n$ 1242) from forty secondary schools of Kerman Province in Iran, 2015

\begin{tabular}{lccc}
\hline \multicolumn{4}{c}{ Consumption of unhealthy snacks } \\
\hline $\mathrm{NCl}$ & $\mathrm{SE}$ & $95 \% \mathrm{Cl}$ & $P$ value \\
\hline 0.179 & 0.015 & $0.056,0.219$ & $<0.001$ \\
\hline
\end{tabular}

variable contributing to the inequality in unhealthy snacks consumption was receiving pocket money allowance (31\%). It was followed by two individual variables: taste and sensory perception (7\%) and cost sensitivity (5\%). Table 3 also represents the residual component. The total NCI of unhealthy snacks consumption was $0 \cdot 179$. The observed component of the total NCI was $0 \cdot 115$. This component indicates that explanatory variables entered in the current model were able to explain $64 \%$ of the measured inequality in unhealthy snacks consumption; that is, environmental and individual factors contributed 51 and $13 \%$ of the observed inequality, respectively. The rest of the inequality (36\%) was the residual component of the total NCI. The residual component implied that there was some inequality in unhealthy snacks consumption which could not be explained by systematic variation in the explanatory variables among SES groups. To be exact, there were other contributors that accounted for this unobserved portion of inequality, but the data for those contributors were not gathered.

\section{Discussion}

The present study tried to shed light on socio-economic inequalities and the contribution of their influencing factors in unhealthy snacks consumption among a sample of adolescent students in Kerman city, located in south-east Iran. 
Table 3 Decomposition of normalized concentration index $(\mathrm{NCl})$ for consumption of unhealthy snacks among eighth-grade adolescent students $(n$ 1242) from forty secondary schools of Kerman Province in Iran, 2015

\begin{tabular}{|c|c|c|c|c|c|}
\hline Variable & Coefficient & Elasticity & $\mathrm{NCl}$ & Absolute contribution & Contribution (\%) \\
\hline Environmental variables & & & & & 66.07 (sum) \\
\hline \multicolumn{6}{|l|}{ Socio-economic status } \\
\hline Poorest ${ }^{*}$ & - & - & - & - & - \\
\hline Poorer & 0.033 & 0.013 & -0.468 & -0.006 & -3.37 \\
\hline Middle & 0.117 & 0.046 & 0.001 & 0.000 & 0.03 \\
\hline Richer & 0.232 & 0.091 & 0.501 & 0.045 & $25 \cdot 37$ \\
\hline Richest & 0.227 & 0.089 & 0.800 & 0.071 & 39.66 \\
\hline Sum & & & & & 61.69 \\
\hline \multicolumn{6}{|l|}{ IHPS programme } \\
\hline Yes* & 0.046 & 0.038 & -0.332 & -0.013 & $-7 \cdot 13$ \\
\hline No & - & - & - & - & - \\
\hline \multicolumn{6}{|l|}{ School type } \\
\hline Private & 0.051 & 0.037 & 0.369 & 0.014 & 7.63 \\
\hline Public* & - & - & - & - & - \\
\hline \multicolumn{6}{|l|}{ Family structure } \\
\hline Dual-parent & -0.086 & -0.154 & 0.187 & -0.029 & -16.03 \\
\hline Single-parent/others* & - & - & - & - & - \\
\hline \multicolumn{6}{|l|}{ Pocket money allowance } \\
\hline Yes & 0.139 & 0.224 & 0.249 & 0.056 & 31.06 \\
\hline $\mathrm{No}^{*}$ & & - & - & - & - \\
\hline \multicolumn{6}{|l|}{ School size } \\
\hline$\leq 150$ & 0.120 & 0.082 & 0.254 & 0.021 & 11.57 \\
\hline $151-300$ & 0.122 & 0.089 & -0.352 & -0.032 & $-17 \cdot 60$ \\
\hline$>300^{*}$ & - & - & - & - & - \\
\hline \multirow{2}{*}{\multicolumn{6}{|c|}{ Snacks sold at school }} \\
\hline & & & & & \\
\hline Yes & 0.012 & 0.020 & -0.007 & 0.000 & -0.08 \\
\hline $\mathrm{No}^{*}$ & - & - & - & - & - \\
\hline \multicolumn{6}{|l|}{ Social norms pressure } \\
\hline Low & -0.082 & -0.118 & 0.057 & -0.007 & -3.74 \\
\hline High* $^{*}$ & - & - & - & - & - \\
\hline \multicolumn{6}{|c|}{ Perceived parental control } \\
\hline Low & 0.052 & 0.073 & -0.042 & -0.003 & $-1 \cdot 68$ \\
\hline High* $^{*}$ & - & - & - & - & - \\
\hline \multicolumn{6}{|l|}{ Media advertisements } \\
\hline High & 0.055 & 0.052 & 0.006 & 0.000 & 0.17 \\
\hline Low $^{*}$ & - & - & - & - & - \\
\hline \multicolumn{6}{|l|}{ Easy accessibility } \\
\hline High & 0.037 & 0.034 & 0.011 & 0.000 & 0.22 \\
\hline Low $^{*}$ & - & - & - & - & - \\
\hline Individual variables & & & & & 13.39 (sum) \\
\hline Gender & & & & & \\
\hline Male & 0.075 & 0.077 & -0.033 & -0.003 & -1.43 \\
\hline Female* & - & - & - & - & - \\
\hline Self-body image & & & & & \\
\hline Very underweight & 0.005 & 0.000 & -0.159 & 0.000 & -0.04 \\
\hline Underweight/fitness & 0.002 & 0.003 & $-0 \cdot 105$ & 0.000 & -0.16 \\
\hline Little overweight & -0.040 & -0.017 & 0.070 & -0.001 & -0.67 \\
\hline Very obese ${ }^{*}$ & - & - & - & - & - \\
\hline Sum & & & & & -0.87 \\
\hline Cost sensitivity & & & & & \\
\hline Very high & -0.047 & -0.032 & 0.244 & -0.008 & $-4 \cdot 33$ \\
\hline High & -0.058 & -0.034 & 0.001 & 0.000 & -0.03 \\
\hline Unsure & -0.180 & -0.086 & -0.166 & 0.014 & 7.99 \\
\hline Low & -0.099 & -0.016 & -0.213 & 0.003 & 1.88 \\
\hline Very low* & - & - & - & - & - \\
\hline Sum & & & & & $5 \cdot 51$ \\
\hline Taste and sensory perc & & & & & \\
\hline High & 0.279 & 0.167 & 0.079 & 0.013 & $7 \cdot 36$ \\
\hline Low $^{*}$ & - & - & - & - & - \\
\hline Perceived self-efficacy & & & & & \\
\hline High & -0.060 & -0.047 & -0.028 & 0.001 & 0.73 \\
\hline Low $^{*}$ & - & - & - & - & - \\
\hline Nutritional knowledge & & & & & \\
\hline High & $-0 \cdot 381$ & -0.374 & -0.010 & 0.004 & 2.09 \\
\hline Low* & - & - & - & - & - \\
\hline Total observed & & & & 0.142 & 79.46 \\
\hline Residual & & & & 0.037 & 20.54 \\
\hline Total & & & & 0.179 & $100 \cdot 00$ \\
\hline
\end{tabular}

IHPS, Iranian Health Promoting School.

*Denotes reference group. 
The study found that unhealthy snacks consumption was unequally distributed among the studied adolescents. Surprisingly, socio-economic inequality in unhealthy snacks consumption concentrated more among the high-SES adolescent students. In terms of the determinants affecting the inequality, there were positive (negative) contributions which decreased (increased) the inequality observed, if the variable were to be equally distributed among various SES groups ${ }^{(30,31)}$. In this regard, an interesting finding was that among the environmental factors, SES and receiving pocket money allowance were influential positive contributors to decreasing inequality in unhealthy snacking consumption, if they were equality distributed across the different SES groups. Thereafter, two positive individual contributors, namely taste and sensory perception and low cost sensitivity, were placed later in a sequential line-up. A systematic review conducted on adolescents and children concluded that high-income and educated populations had an unhealthy diet ${ }^{(32)}$. Another study conducted in Brazil showed that foods rich in fat, salt and sugar were positively associated with SES among adolescents ${ }^{(33)}$.

It has also been shown that unhealthy snacks consumption is associated with weight gain ${ }^{(7)}$. In this regard, some studies conducted in $\operatorname{Iran}^{(34,35)}$ concluded that obesity and overweight were more prevalent in children and adolescents with more affluent and well-educated parents, indicating that they highly consumed unhealthy snacks and junk foods. Furthermore, one systematic review of studies conducted on the association between SES and obesity among children and adolescents concluded that higherSES groups in most developing countries with varied income levels and socio-economic measures, including Iran, India, Vietnam, Ukraine, Colombia, Sri Lanka, South Africa and Guatemala, had more overweight and obesity compared with lower-SES groups ${ }^{(36)}$. In contrast, such an association was mostly inverse in developed countries ${ }^{(37,38)}$, indicating that the consumption pattern of unhealthy snacks by SES was not the same in developing and developed countries. This heterogeneity might be due to at least two reasons.

First, some important factors affecting obesity are food quality, prices and availability in a community ${ }^{(39)}$. In this regard, our study highlighted that families with higher economic, educational and job status, who consequently spent less time in family activities and parenting children than in paid work, had more consumption of junk foods. A study conducted by Bauer et al. also concluded that employed mothers and fathers reported less time spent on food preparation, and employed mothers reported having fewer family meals, less frequent encouragement of their adolescents' healthful eating, and lower and fruit and vegetable intake, compared with not-employed mothers, after adjusting for sociodemographic factors ${ }^{(40)}$.

Second, more affluent adolescents spend more time with their friends in coffee shops and fast-food restaurants, providing opportunities to higher consumption of unhealthy snacks, particularly with regard to the fact that eating is an important expressive of socialization and recreation ${ }^{(22,41)}$. Another important finding in the present study was that pocket money allowance might increase a risk for the inequality of unhealthy snacks consumption among adolescents with higher SES. This is because adolescents living in families with higher SES most likely received more pocket money allowance and this directly affected their food choices. This result is also supported by Haye et $a l^{(42)}$ and Li et al. ${ }^{(43)}$ who concluded that pocket money was associated with higher intake of sugary beverages, fast foods or foods at street-food stalls.

The current study found that the good taste and sensory perceptions of junk foods, compared with healthy ones, were additional factors contributing to the increased inequality in unhealthy snacks consumption among higher SES. This view was also echoed by previous research which delineated a 'healthy= less tasty' intuition. The intuition resulted in consumers' feeling to perceive foods called healthy as less tasty than the same food called unhealthy and vice versa ${ }^{(44)}$. Of course, evidence shows that focusing on both healthiness and tastiness of healthy foods ${ }^{(45)}$ and the role of health consciousness ${ }^{(46)}$ may lead consumers to healthier decisions.

In the case of cost sensitivity, the current study found that low cost (price) sensitivity increased the inequality of unhealthy snacking behaviours among adolescents with higher SES. A possible explanation for this might be that the cost and price of unhealthy and junk foods in Iran are at the extent which would not reduce demands for buying them by adolescents with higher SES. This was also proved by a meta-analysis which concluded that less healthy foods had lower costs than healthier ones ${ }^{(47)}$. A key policy priority should therefore be to plan for taxing unhealthy snacks and junk foods so that the taxation levels would have a significant effect on reducing consumption of unhealthy snacks. Mytton et al. examined the evidence and found that generally imposing taxes on unhealthy foods might decrease unhealthy snacks consumption ${ }^{(48)}$. Of course, it was shown that poorer individuals are more sensitive to price changes ${ }^{(49,50)}$. Therefore, in order to decrease the consumption of unhealthy snacks, as suggested by evidence, the tax should be at least $20 \%$ to have a significant effect on population health ${ }^{(48)}$. In brief, adolescents with higher SES consume both healthy and unhealthy snacks more ${ }^{(22)}$, since they have financial means and easy access to such snacks.

\section{Study strengths and limitations}

A strength of the present study was its novelty as it is the first conducted on inequality analysis of unhealthy snacks consumption. In the study, we utilized a composite index as a proxy variable of SES to estimate and decompose inequality. The composite index encompassed most key indicators known for SES of adolescents including parental education 
level, parental employment status, and household income and conditions, as supported by Galobardes et al. ${ }^{(51)}$. This composite index enabled us to obtain a variable highly reflective of an adolescent's SES. The study also had some limitations that should be kept in mind. First, although we utilized a relatively large-scale population based on sampling which might result in more internal validity, the participants were not sufficiently representative of Iranian adolescent students due to the heterogeneity in the population. Therefore, we suggest further research on the inequality of unhealthy snacks consumption at national and provincial levels in Iran. Second, as there was no cut-off point for what should be considered high unhealthy snacks consumption, we used the median as a cut-off to group the students into two categories of high and low unhealthy consumption. This might affect our findings in some ways and requires careful and cautious consideration to interpret the results. Future studies in Iran are necessary to define a standard cut-off point for the consumption of unhealthy snacks. Finally, as the data were extracted from a cross-sectional study, any causal interpretations should be made with caution, as longitudinal or experimental studies can better explore such attributions.

\section{Implications for policy makers}

1. Measuring inequality of unhealthy snacks consumption and decomposing the contributing factors help policy makers to adopt tailored policies for tackling inequality in food consumption.

2. The most important contributors to inequality of unhealthy snacks consumption, disfavouring the high-SES adolescents, were attributable to individual and environmental factors including SES, receiving pocket money allowance, better taste and sensory perception, and low cost sensitivity.

3. It is suggested that policy makers account for taxing of unhealthy and junk foods to control the demands for them by higher-SES populations.

\section{Conclusion}

We conclude that health promotion strategies should be applied not only at environmental and individual levels, but also at different settings including schools, families and suppliers of unhealthy snacks. This implicitly pinpoints the key role of schools, where adolescents spend a considerable time of their lives every day, to adopt tailored health promotion policies. In this regard, it is suggested that private schools, where adolescents with higher SES attend more, should raise knowledge, promote the consumption of healthy snacks and limit the consumption of unhealthy ones. This would be facilitated by a collaborative approach among parents, schools' staff and food suppliers.

\section{Acknowledgements}

Acknowledgements: The authors greatly thank Mr Keivan Rahmani for help preparing the initial draft of this manuscript. Financial support: This work was supported by the Kerman University of Medical Sciences (grant number 95/341). Kerman University of Medical Sciences contributed to the study design and conduct of the study. Conflict of interest: None. Authorship: V.Y.-F. formulated the research question, designed the study and carried it out with contribution from A.R. M.A.R. analysed the data and interpreted the results. V.Y.-F. and M.A.R. wrote the manuscript draft and revised the final version. Ethics of buman subject participation: This study was conducted according to the guidelines laid down in the Declaration of Helsinki and all procedures involving research study participants were approved by the Kerman University of Medical Sciences Research Ethics Committee (ethical code number IR.KMU.1395.568). Written informed consent was obtained from all subjects.

Author ORCID. (D) Mostafa Amini Rarani, 0000-00024809-2237.

\section{References}

1. Duffey KJ, Pereira RA \& Popkin BM (2013) Prevalence and energy intake from snacking in Brazil: analysis of the first nationwide individual survey. Eur J Clin Nutr 67, 868-874.

2. Ovaskainen ML, Tapanainen H \& Pakkala H (2010) Changes in the contribution of snacks to the daily energy intake of Finnish adults. Appetite 54, 623-626.

3. Ovaskainen ML, Reinivuo H \& Tapanainen H et al. (2006) Snacks as an element of energy intake and food consumption. Eur J Clin Nutr 60, 494-501.

4. World Health Organization (2015) WHO Regional Office for Europe Nutrient Profile Model. Copenhagen: WHO Regional Office for Europe; available at http://www.euro.who.int/ __data/assets/pdf_file/0005/270716/Nutrient-children_webnew.pdf?ua $=1$

5. Community Nutrition Improvement Office \& Health Affairs Office (2014) National Guideline for Healthy Food Canteen in Schools. Tehran: Community Nutrition Improvement Office and Health Affairs Office; available at http://www. iribnews.ir/files/fa/news/1396/7/15/1451249_457.pdf

6. Fismen AS, Smith ORF \& Samdal O (2014) A school based study of time trends in food habits and their relation to socio-economic status among Norwegian adolescents, 2001-2009. Int J Behav Nutr Phys Act 11, 115.

7. Bagherniya M, Sharma M \& Mostafavi F et al. (2015) Application of social cognitive theory in predicting childhood obesity prevention behaviors in overweight and obese Iranian adolescents. Int Q Community Health Educ 35, 133-147.

8. Payab M, Kelishadi R \& Qorbani M et al. (2015) Association of junk food consumption with high blood pressure and obesity 
in Iranian children and adolescents: the CASPIAN-IV Study. J Pediatr (Rio J) 91, 196-205.

9. Esteghamati A, Khalilzadeh O \& Mohammad K et al. (2010) Secular trends of obesity in Iran between 1999 and 2007: National Surveys of Risk Factors of Non-communicable Diseases. Metab Syndr Relat Disord 28, 209-213.

10. Kelishadi R, Haghdoost AA \& Sadeghirad B et al. (2014) Trend in the prevalence of obesity and overweight among Iranian children and adolescents: a systematic review and meta-analysis. Nutr 30, 393-400.

11. Jafari-Adli S, Jouyandeh Z \& Qorbani M et al. (2014) Prevalence of obesity and overweight in adults and children in Iran; a systematic review. J Diabetes Metab Disord 13, 121.

12. Due P, Krølner R \& Rasmussen M et al. (2011) Pathways and mechanisms in adolescence contribute to adult health inequalities. Scand J Public Health 39, 62-78.

13. Dowler E (2001) Inequalities in diet and physical activity in Europe. Public Health Nutr 4, 701-709.

14. Marmot M (2005) Social determinants of health inequalities. Lancet 365, 1099-1104.

15. Méjean C, Droomers M \& van der Schouw YT et al. (2013) The contribution of diet and lifestyle to socioeconomic inequalities in cardiovascular morbidity and mortality. Int J Cardiol $\mathbf{1 6 8}$ 5190-5195.

16. Mackenbach JP, Stirbu I \& Roskam AJR et al. (2008) Socioeconomic inequalities in health in 22 European countries. N Engl J Med 358, 2468-2481.

17. Pampel FC, Krueger PM \& Denney JT (2010) Socioeconomic disparities in health behaviors. Annu Rev Sociol 36 , 349-370.

18. Sawyer SM, Afifi RA \& Bearinger LH et al. (2012) Adolescence: a foundation for future health. Lancet 379, 1630-1640.

19. Yazdi-Feyzabadi V, Keshavarz Mohammadi N \& Omidvar N et al. (2017) Factors associated with unhealthy snacks consumption among adolescents in Iran's schools. Int J Health Policy Manag 6, 519-528.

20. Lindström M, Hanson BS \& Wirfält E et al. (2001) Socioeconomic differences in the consumption of vegetables, fruit and fruit juices: the influence of psychosocial factors. Eur J Public Health 11, 51-59.

21. Story M, Neumark-Sztainer D \& French S (2002) Individual and environmental influences on adolescent eating behaviors. J Am Diet Assoc 102, 3 Suppl., S40-S51.

22. Yazdi-Feyzabadi V, Omidvar N \& Keshavarz Mohammadi N et al. (2017) Is an Iranian Health Promoting School status associated with improving school food environment and snacking behaviors in adolescents? Health Promot Int 33 , 1010-1021.

23. Vyas S \& Kumaranayake L (2006) Constructing socio-economic status indices: how to use principal components analysis. Health Policy Plan 21, 459-468.

24. O'Donnell O, Van Doorslaer E \& Wagstaff A et al. (2007) Analyzing Health Equity Using Household Survey Data: A Guide to Techniques and Their Implementation. Washington, DC: The World Bank; available at http://siteresources. worldbank.org/INTPAH/Resources/Publications/4598431195594469249/HealthEquityFINAL.pdf

25. Friel S, Kelleher CC \& Nolan G et al. (2003) Social diversity of Irish adults nutritional intake. Eur J Clin Nutr 57, 865-875.

26. Amini Rarani M, Rashidian A \& Khosravi A et al. (2017) Changes in socio-economic inequality in neonatal mortality in Iran between 1995-2000 and 2005-2010: an Oaxaca decomposition analysis. Int $J$ Health Policy Manag 6, 219-228.
27. Wagstaff A (2005) The bounds of the concentration index when the variable of interest is binary, with an application to immunization inequality. Health Econ 14, 429-432.

28. Wagstaff A, van Doorslaer E \& Watanabe N (2003) On decomposing the causes of health sector inequalities with an application to malnutrition inequalities in Vietnam. $J$ Econom 112, 207-223.

29. Yiengprugsawan V, Lim LLY \& Carmichael GA et al. (2010) Decomposing socioeconomic inequality for binary health outcomes: an improved estimation that does not vary by choice of reference group. BMC Res Notes 3, 57.

30. Zhang Q \& Wang Y (2007) Using concentration index to study changes in socio-economic inequality of overweight among US adolescents between 1971 and 2002. Int J Epidemiol 36, 916-925.

31. Omani-Samani R, Rarani MA \& Sepidarkish M et al. (2018) Socioeconomic inequality of unintended pregnancy in the Iranian population: a decomposition approach. $B M C$ Public Health 18, 607.

32. Hinnig PF, Monteiro JS \& de Assis MAA et al. (2018) Dietary patterns of children and adolescents from high, medium and low human development countries and associated socioeconomic factors: a systematic review. Nutrients 10, 436.

33. Borges CA, Slater B \& Santaliestra-Pasías AM et al. (2018) Dietary patterns in European and Brazilian adolescents: comparisons and associations with socioeconomic factors. Nutrients 10, 57.

34. Maddah M \& Nikooyeh B (2010) Factors associated with overweight in children in Rasht, Iran: gender, maternal education, skipping breakfast and parental obesity. Public Health Nutr 13, 196-200.

35. Shafaghi K, Shariff ZM \& Taib MNM et al. (2014) Parental body mass index is associated with adolescent overweight and obesity in Mashhad, Iran. Asia Pac J Clin Nutr 23, 225-231.

36. Dinsa GD, Goryakin Y \& Fumagalli E et al. (2012) Obesity and socioeconomic status in developing countries: a systematic review. Obes Rev 13, 1067-1079.

37. Hulshof K, Brussaard JH \& Kruizinga AG et al. (2003) Socioeconomic status, dietary intake and 10 y trends: the Dutch National Food Consumption Survey. Eur J Clin Nutr 57, $128-137$.

38. Wang Y \& Lim H (2012) The global childhood obesity epidemic and the association between socio-economic status and childhood obesity. Int Rev Psychiatry 24, $176-188$

39. Cummins S \& Macintyre S (2006) Food environments and obesity - neighbourhood or nation? Int J Epidemiol 35, 100-104.

40. Bauer KW, Hearst MO \& Escoto $\mathrm{K}$ et al. (2012) Parental employment and work-family stress: associations with family food environments. Soc Sci Med $\mathbf{7 5}$, 496-504.

41. Sawka KJ, McCormack GR \& Nettel-Aguirre A et al. (2013) Friendship networks and physical activity and sedentary behavior among youth: a systematized review. Int J Behav Nutr Phys Act 10, 130.

42. Haye K, Robins G \& Mohr P et al. (2013) Adolescents' intake of junk food: processes and mechanisms driving consumption similarities among friends. $J$ Res Adolesc 23, 524-536.

43. Li M, Xue H \& Jia P et al. (2017) Pocket money, eating behaviors, and weight status among Chinese children: the Childhood Obesity Study in China mega-cities. Prev Med 100, 208-215. 
44. Raghunathan R, Naylor RW \& Hoyer WD (2006) The unhealthy = tasty intuition and its effects on taste inferences, enjoyment, and choice of food products. J Mark 70, 170-184.

45. Petit O, Merunka D \& Anton JL et al. (2016) Health and pleasure in consumers' dietary food choices: individual differences in the brain's value system. PLoS One 11, e0156333.

46. Mai R \& Hoffmann S (2015) How to combat the unhealthy= tasty intuition: the influencing role of health consciousness. J Public Policy Mark 34, 63-83.

47. Rao M, Afshin A \& Singh G et al. (2013) Do healthier foods and diet patterns cost more than less healthy options? A systematic review and meta-analysis. BMJ Open 3, e004277.
48. Mytton OT, Clarke D \& Rayner M (2012) Taxing unhealthy food and drinks to improve health. BMJ 344, e2931.

49. Powell LM \& Chaloupka FJ (2009) Food prices and obesity: evidence and policy implications for taxes and subsidies. Milbank Q 87, 229-257.

50. Smed S, Jensen JD \& Denver S (2007) Socio-economic characteristics and the effect of taxation as a health policy instrument. Food Policy 32, 624-639.

51. Galobardes B, Shaw M \& Lawlor DA et al. (2006) Indicators of socioeconomic position (part 1). J Epidemiol Community Health 60, 7-12. 